\title{
AMAZONAS
}

DOI: https://doi.org/10.34069/RA/2021.7.06

Volumen 4, Número 7/enero-junio 2021

\section{Diseño de una ruta turística por el legado africano de Yaguajay como vía para el desarrollo local}

\author{
Design of a tourist route through the African legacy of Yaguajay as a way for \\ local development
}

Recibido: 1 de enero de $2021 \quad$ Aceptado: 25 de abril de 2021

\author{
Autores: \\ Miguel Alejandro Delgado Méndez ${ }^{16}$ \\ Sinaí Boffill Vega ${ }^{17}$ \\ Jady Yemila Selki González ${ }^{18}$ \\ Martha Aleida Picayo Delgado ${ }^{19}$
}

\section{Resumen}

El desarrollo del turismo ha venido impulsando dimensiones fuera de su tradicional convencionalismo. Su vinculación a prácticas de desarrollo local ha sido una de las variantes más recurridas a nivel internacional. Cuba como país subdesarrollado, se inserta en esta concepción y propone estrategias de desarrollo a partir de sus recursos endógenos. El municipio Yaguajay, ha sido pionero en este sentido y la investigación que se presenta da continuidad a estudios anteriores, que trataron los temas de revitalización del patrimonio industrial azucarero para fomentar el turismo cultural y acciones para la salvaguarda de tradiciones afrocubanas en el Barrio África. Sin embargo, la presente investigación tiene el objetivo de diseñar una ruta turística por el legado africano de Yaguajay como vía de desarrollo local. Para su realización se utilizó una metodología cualitativa principalmente, donde la utilización de métodos y técnicas de este paradigma ayudaron a realizar una sistematización teórica-conceptual sobre el tema y a obtener los resultados. Se realizó un diseño, donde se valoraron los criterios de pertinencia, flexibilidad, contextualización, accesibilidad entre otros. La creación de un mapa temático de recorrido, un logo de imagen turística, actividades y servicios que coadyuvan en la elaboración de una ruta competitiva; así como; sugerencias para la capacitación a los prestadores de servicios turísticos, la señalización de atractivos, distancias y sitios y la propuesta de operación de la ruta; constituyen los principales resultados de la investigación y las estrategias que se recomienda utilizar para implementar y posicionar la ruta turística por el legado africano de Yaguajay.

Palabras clave: legado africano, ruta turística, Yaguajay.

\footnotetext{
16 Parque Nacional Caguanes. CSASS. CITMA. Máster en Gestión del Desarrollo Local. Universidad José Martí. Centro Universitario Municipal "Simón Bolívar". Municipio Yaguajay. Provincia Sancti-Spíritus. País Cuba. ORCID: https://orcid.org/0000-0002-5652-1185

17 Doctora en Ciencias. Profesora Titular. Universidad José Martí. Centro Universitario Municipal "Simón Bolívar". Municipio Yaguajay. Provincia Sancti-Spíritus. País Cuba. ORCID: https://orcid.org/0000-0001-8389-4756

${ }^{18}$ Máster en Gestión del Desarrollo Local. Profesor Instructor. Universidad José Martí. Centro Universitario Municipal "Simón Bolívar". Municipio Yaguajay. Provincia Sancti-Spíritus. País Cuba. ORCID: https://orcid.org/0000-00026026-2091

19 Máster en Ciencias de la Educación. Profesor Auxiliar. Universidad José Martí. Centro Universitario Municipal "Simón Bolívar". Municipio Yaguajay. Provincia Sancti-Spíritus. País Cuba. ORCID: https://orcid.org/0000-00023127-8684
} 


\title{
AMAZÓNAS
}

\begin{abstract}
The development of tourism has been promoting dimensions outside its traditional conventionality. Its link to local development practices has been one of the most widely used variants at the international level. Cuba, as an underdeveloped country, is inserted in this conception and proposes development strategies based on its endogenous resources. The Yaguajay municipality has been a pioneer in this sense and the research presented gives continuity to previous studies, which dealt with the revitalization of the industrial sugar heritage to promote cultural tourism and actions to safeguard Afro-Cuban traditions in the Africa neighborhood. However, the present research aims to design a tourist route through the African legacy of Yaguajay as a way of local development. For its realization, a qualitative methodology was used mainly, where the use of methods and techniques of this paradigm helped to carry out a theoretical-conceptual systematization on the subject and obtain the results. A design was made, where the criteria of relevance, flexibility, contextualization, accessibility, among others, were assessed. The creation of a thematic route map, a tourist image logo, activities and services that contribute to the development of a competitive route; ASI como; suggestions for the training of tourist service providers, the marking of attractions, distances and sites and the proposal for the operation of the route; constitute the main results of the research and the strategies that are recommended to be used to implement and position the tourist route for the African legacy of Yaguajay.
\end{abstract}

Keywords: African legacy, tourist route, Yaguajay.

\section{Introducción}

El mundo actual se encuentra viviendo un proceso dinámico y a la vez complejo, donde el neoliberalismo, representado en su máxima expresión: la globalización, ha homogenizado las diferencias económicas, políticas, sociales, tecnológicas y culturales, entre las naciones; específicamente las desarrolladas vs subdesarrolladas. Los países optan por alternativas económicas en un mercado cada vez más global y competitivo.

El turismo es una de las actividades que ha prosperado en el mundo contemporáneo gracias a múltiples factores. Cada día son más las opciones y territorios que se incorporan al desarrollo de esta lucrativa actividad económica, lo que paralelamente, incrementa la oferta de nuevos productos turísticos (Pelegrín, Sabín, y Martínez, 2018). Históricamente los llamados países del primer mundo acaparan y manejan un gran porciento de este fenómeno, incluso fuera de sus fronteras.

En este contexto los estados en vías de desarrollo y algunos subdesarrollados se lanzaron a proponer sus variantes turísticas identitarias en detrimento al turismo convencional o a gran escala. En economías pequeñas como es el caso de Cuba, la actividad económica, enfocada al turismo, toma mayor importancia para su desarrollo y el aumento de la calidad de vida de las personas, al no contar, por ejemplo, con amplios recursos naturales, ni gran infraestructura industrial (Hernández, 2019).

Cuba representa uno de los destinos turísticos de mayor crecimiento en la actualidad dentro del área caribeña, debido entre otros factores, a su cantidad, variedad de atractivos, recursos de interés en este sentido y ubicación privilegiada en el contexto geográfico del Caribe Insular y Centroamérica (Salinas et al, 2019). El patrimonio histórico-cultural ha sido una de las propuestas cubanas. El mismo cuenta con innumerables bienes tangibles e intangibles que pueden ser valorados a favor de un turismo menos dañino para los ecosistemas. 
Cuba como país subdesarrollado han buscado en este patrimonio vías de desarrollo. Específicamente, las relacionadas a su tradición histórica; donde el proceso de colonización, trajo consigo un fenómeno cultural, en el que se desarrolló una mezcla de etnos y los africanos fueron determinantes; ha sido una de estas ideas para fomentar el desarrollo. Este proceso es conocido por la historiografía como transculturación.

Los estudios sobre el legado africano en el mundo, como ente del patrimonio históricocultural, son diversos y desde distintos enfoques, debido, entre otros factores, a un proceso de colonización, trata y descolonización que vivió el continente africano en siglos pasados. Desde otro enfoque, ayudó a la conformación cultural de varios territorios, desenlazándose un proceso de transculturación. América fue uno de los continentes de mayor recepción de negros esclavos, dado por su característica de "tierra descubierta" y rica en recursos naturales.

Esta visión, está siendo complementada desde hace ya varios años con una perspectiva de Desarrollo Local, donde se aproveche los recursos culturales, tangibles e intangibles hereditarios de la presencia africana en el mundo. Cuba se ha incorporado a esta mirada; ejemplo fehaciente de ello es el desarrollo del proyecto "Ruta del Esclavo", avalado por la UNESCO, donde uno de sus principales objetivos es: "identificar donde hubo presencia africana en el territorio, del mismo modo, deja explicito la necesidad de acercar culturalmente el continente africano con sus diásporas, siguiendo un diálogo mutuo y sincero" (Guanche y Barnet, 2009). De igual modo, se ajusta a lo plasmado en el VII Congreso del Partido Comunista de Cuba (PCC), donde se promueve el desarrollo local y el uso de los recursos turísticos de manera eficiente (PCC, 2016).

El municipio Yaguajay, provincia Sancti Spíritus, fue una de las zonas cubanas que experimentó la presencia del negro africano, vinculada principalmente al azúcar, al igual que en la mayoría del país. Esta representación, se encuentra evidenciada en componentes tangibles e intangibles que conforman parte del patrimonio histórico-cultural de la localidad.

Entre los más representativos, se encuentran los restos de los antiguos trapiches e ingenios, elementos constructivos de los mismos: barracones, torres de ingenio, pozos con sus norias $^{20}$, tanques de almacenamiento de agua, muelles marítimos, líneas férreas; o sea, toda una infraestructura de producción azucarera.

Existen evidencias arqueológicas como peinetas, cachimbas, esposas y grilletes de manos y pies, respectivamente. Se transfiere a la actualidad municipal rasgos de la superestructura religiosa, identificándose algunos yaguajayenses con los cultos característicos de los africanos; representándose en el territorio toda una cultura inmaterial permeada de raíces africanas.

La utilización de estos espacios, como parte del patrimonio histórico cultural del municipio, con su determinado plan de manejo y conservación, están contenidos dentro del documento: "Estrategia de Desarrollo Yaguajay. Propuesta de Actualización", específicamente en el punto seis, referido a identificar las potencialidades del patrimonio a favor de la explotación turística (Grupo de Desarrollo Local, 2016).

Asimismo, estas evidencias -tangibles e intangibles- que forman parte del patrimonio histórico-cultural de Yaguajay han sido tratadas en investigaciones precedentes, resultados de la primera edición del Programa de la Maestría en Gestión del Desarrollo Local, como en el caso de las autoras (Borroto, 2017) y (Font, 2017). Apoyados en los resultados de ambos estudios y otros que demuestran las potencialidades del legado africano el objetivo de la presente investigación

${ }^{20}$ Artefacto, parecido a una rueda, mediante el cual, manualmente o a través de fuerza animal sacaban el agua de los pozos para su posterior uso en la producción de la azúcar. 


\section{AMAZđ̛́NAS}

consiste en diseñar una ruta turística por los principales espacios donde se ha evidenciado el legado africano en Yaguajay como alternativa para contribuir al desarrollo local.

\section{Marco teórico}

El término patrimonio es utilizado en el mundo para referirse esencialmente a dos cuestiones. Una, desde el punto de vista jurídico, la que no constituye objeto de estudio. Por otro lado, se relaciona a un bien material o inmaterial, casi siempre relacionado a un fenómeno o proceso histórico o cultural. Estas dos denominaciones se pueden observar en la historiografía y en algunas bibliografías acompañadas de la palabra patrimonio, en la mayoría de los casos para no confundirlo con la dimensión jurídica que posee.

Con el adelanto de las ciencias sociales, evidenciado en las disímiles investigaciones y publicaciones en diversos medios; los debates sobre el patrimonio se han enriquecido. La Convención sobre la Protección del Patrimonio Mundial Cultural y Natural adoptada por la Conferencia General de la Organización de las Naciones Unidas para la Educación, la Ciencia y la Cultura (UNESCO), realizada el 16 de noviembre de 1972 y cuyo objetivo fue promover la identificación, protección y preservación del patrimonio cultural y natural de todo el mundo, el cual es considerado especialmente valioso para la humanidad; fue lo que otorgó valides objetiva e institucional al patrimonio como capital de un país e incluso de la humanidad (Unesco, 1972).

A partir de entonces han surgidos conceptos relacionados con el patrimonio industrial, cultural, histórico, industrial, arquitectónico, nacional, musical, entre otros. No se pretende analizar los presupuestos conceptuales relacionados al patrimonio; solo los que se acercan a los objetivos de la investigación.

Hasta el momento, no se ha localizado un concepto que englobe en sí lo que es patrimonio histórico-cultural. Si entendemos, patrimonio histórico, “el conjunto de bienes, tanto materiales como inmateriales, acumulados a lo largo de la historia. Estos bienes pueden ser artísticos, históricos, arqueológicos, paleontológicos, documentales, científico o técnico" (Castelli et al, 2007). Patrimonio cultural es entendido, "como la herencia cultural propia de una comunidad, con la que ésta vive en la actualidad y que trasmite a las generaciones presentes y futuras" (Castelli et al, 2007).

El patrimonio histórico-cultural de un país, región, ciudad e incluso lugar está formado por todos aquellos componentes y manifestaciones tangibles o intangibles originadas por las sociedades en relación con el ambiente donde se desenvuelven y son resultado de un proceso auténtico que identifican y muestran las particularidades del país, región, ciudad o lugar.

El patrimonio tangible e intangible, es uno de los recursos más obvios y notables en el marco de las posibilidades que posee un territorio para articular estrategias de desarrollo a partir de su sector cultural (Rausell, 2007). La representación intangible del patrimonio, también denominada inmaterial o simbólica es la más compleja en cuanto a la subjetividad que supone.

El Patrimonio Histórico-Cultural como recurso del desarrollo local, incorpora visita a museos, yacimientos arqueológicos, edificios civiles, militares, religiosos o industriales, centros históricos. De igual forma incorporan manifestaciones de la cultura tradicional y popular, la gastronomía, danza u ópera, realización de estancias para el aprendizaje de idiomas, entre otros elementos. (De Mahieu et al, 2003)

Desde la perspectiva apuntada y entrevistas semiestructuradas aplicadas durante el proceso de investigación; el legado africano, evidenciado en espacios tangibles e intangibles, constituye un elemento a considerar dentro del patrimonio histórico-cultural de un territorio. La 
utilización de estos espacios, con su determinado plan de manejo y conservación pueden forman parte de las estrategias de desarrollo local de una zona donde se evidencien elementos en este sentido.

\section{Legado Africano como patrimonio material e inmaterial}

El legado africano, está asociado a la presencia actual de evidencias tangibles e intangibles relacionadas a un fenómeno conocido mundialmente como: "colonización", resultado este de un proceso colonialista donde de un país o territorio ${ }^{21}$ es dominado por parte de otro $^{22}$. Este proceso puede ser de carácter económico, político, militar, cultural, o presentar otras manifestaciones; así como desarrollarse de forma violenta o pacífica. Como parte inseparable de este proceso se desarrolló la trata negrera, una de las principales variantes de esclavitud.

Es pertinente destacar que, en el discurso de la investigación, se aborda indistintamente la palabra esclavitud, no obstante, se utiliza para referirse a las consecuencias que trajo la africana solamente, es por ello, que se maneja el término legado africano. ${ }^{23}$

La Ruta del Esclavo, impulsado por la UNESCO hace años de veinte años, es un proyecto que se ha enriquecido, retroalimentado y evolucionado la mirada sobre el legado africano. Cuba como parte indiscutible de este proyecto, se ha incorporado a esta mirada, donde uno de sus principales objetivos es: "identificar donde hubo presencia africana en el territorio, del mismo modo, deja explicito la necesidad de acercar culturalmente el continente africano con sus diásporas, siguiendo un diálogo mutuo y sincero" (Guanche y Barnet, 2009, pág. 2).

En cuanto al papel desempeñado por la cultura en el desarrollo local, se destacaron algunas buenas prácticas, las cuales muestran el grado del impacto que supone la integración de expresiones culturales afroamericanas en proyectos comunitarios con el fin de alcanzar el progreso socioeconómico, particularmente, en el campo de la salud (Guanche, 2010).

Otro punto dentro de la curva del itinerario histórico plasmado en el proyecto es; promover el turismo basado en este patrimonio. El legado africano como uno de los componentes estructurales del patrimonio histórico-cultural de una nación, puede ser utilizado como una vía para fomentar el turismo, siendo un elemento catalizador, al ser una forma diferente de disfrute e insertarse en unas de las tendencias turísticas actuales.

\section{Tendencias turísticas en favor del desarrollo local}

Las tendencias turísticas han venido cambiando, el nivel cultural de los consumidores ha evolucionado. Dirigen su atención las ofertas del turismo cultural y dentro de este, el patrimonial, histórico, de naturaleza, agroturismo, ecológico, entre otros. Estas directrices que ha tomado el turismo mundial, se encuentran teóricamente sobre la base de estudios realizados por especialistas del tema. Exponen una relación, sinergia, incluso los más radicales, hablan de tránsito del turismo caracterizado por la amplia masividad del consumo; definido por turismo fordista, hacia un escenario dinámico, donde los destinos compiten en un mercado global, oferta especializada, exigente; turismo post-fordista (Nogueda, 2016)

El desarrollo local del turismo se convierte en las comunidades en un espacio de contradicciones donde los distintos sectores implicados no necesariamente tienen los mismos intereses, sino que más de una vez, por el contrario, sostienen claramente posiciones opuestas. A

\footnotetext{
${ }^{21}$ Queda recogido en la literatura el nombre de Colonia para referirse a estos lugares.

${ }^{22}$ Queda recogido en la literatura el nombre de Metrópoli para referirse a estos lugares.

23 Téngase en cuenta que producto de la trata, no solo entraron esclavos negros a América, sino también chinos, árabes, e incluso europeos.
} 


\section{AMAZÓNAS}

esto se suma la fragilidad de los recursos en los que se basa el turismo, así como la creciente demanda de una mayor calidad medioambiental y el hecho de que el turismo es una actividad ambivalente, que puede aportar grandes ventajas en el ámbito socioeconómico y cultural, mientras que al mismo tiempo contribuye a la degradación medioambiental y a la pérdida de la identidad local (Ponce et. al., 2018).

Por otro lado, la puesta en práctica de cualquier argumento turístico, resulta complejo, debido, entre otras razones a que median diversos elementos; dígase: comercialización, alimentación, alojamiento, propuesta de actividades y rehabilitación de espacios. Sin embargo, esta gama de relaciones, que se tiene que proporcionar inevitablemente para un desarrollo turístico, resulta de gran importancia económica y social, no solo para economías desarrolladas, sino también para aquellas en vías de desarrollo, proporciona una importante fuente para la captación de divisas y una manera para acceder a inversiones y generar empleos (Zulueta, 2015).

El nuevo contexto nacional e internacional abogado hacia las nuevas políticas de descentralización y apertura de la industria turística hacia otros derroteros ha contribuido a que Cuba se encuentre viviendo un proceso de desarrollo turístico sin precedentes, impulsado, entre otras causas, por las iniciativas locales de desarrollo.

El turismo en Cuba como vía de desarrollo local, se muestra difuso en algunos territorios y a la vez práctico y necesario. Se debe a que es una tendencia en su evolución y a la penuria de los municipios de potenciar el turismo basado en sus propios recursos y atractivos, y de esa forma lograr un mayor beneficio, tanto económico, como ambiental y social (Brito, 2011).

Se abordan los conceptos de Turismo Patrimonial y Turismo Cultural, debido al acercamiento de estos con la propuesta de investigación; a la vez que esta se inserta en dichos conceptos. Se entiende por Turismo Patrimonial al desplazamiento de personas motivadas por el interés especial que presentan los recursos patrimoniales de un lugar o zona específica. Aporta beneficios a la comunidad anfitriona y motiva el cuidado de sus bienes culturales y las tradiciones vivas mediante un compromiso entre la ciudadanía, los empresarios turísticos y las entidades públicas relacionadas, en post de gestionar los sitios patrimoniales para un uso turístico sustentable, aumentando su protección en beneficio de las generaciones futuras (De Madariaga, \& Asencio, 2018)

De igual forma, la Organización Mundial del Turismo define al Turismo Cultural de dos maneras. En sentido estricto, se refiere a movimiento de personas debido esencialmente a motivos culturales como viajes de estudios, viajes a festivales u otros eventos culturales, visitas a sitios y monumentos, viajes para estudiar la naturaleza, el arte o el folclore, y peregrinaciones. (Domínguez, García y Barrientos, 2019)

El Turismo Cultural pone en valor la cultura local y a ciertos elementos pertenecientes a las manifestaciones y particularidades locales, los cuales, por sí solos o en conjunto con otros, motivarán al turista a desplazarse para conocerlos. La puesta en valor de los atractivos, ya sean culturales o naturales, requiere de planificación para preservar, conservar y mantener sus características originales, que son las que finalmente motivan al turista a movilizarse (Domínguez, García y Barrientos, 2019).

Como se puede comprender el concepto Turismo Cultural es mayor que el Turismo Patrimonial en cuanto a su alcance e infraestructura a crear. Este último se basa esencialmente en el disfrute y visualización del patrimonio como fuente placentera de realizar turismo. No obstante, la creación de nuevos productos turísticos que aprovechen los recursos patrimoniales para diferenciar la oferta de un destino es esencial para aumentar la satisfacción del turista, así como su lealtad y fidelidad hacia este (Cardet, Palao y González, 2018). 


\section{AMAZÓNAS}

\section{Rutas Turísticas}

El desarrollo del turismo tiene múltiples impactos, en la comunidad donde se realiza, que van desde lo económico, social o ambiental (Santos, 2017). La creación de rutas turísticas se está convirtiendo en una vía de impulso al desarrollo sustentable, concibiendo este como:

"un proceso de elevación sostenida y equitativa de la calidad de vida de las personas, mediante el cual se procura el crecimiento económico y el mejoramiento social, en una combinación armónica con la protección del medio ambiente, de modo que se satisfacen las necesidades de las actuales generaciones, sin poner en riesgo la satisfacción de las necesidades de las generaciones futuras" (Ley $\left.\mathrm{N}^{\circ} 81,1997\right)$.

El concepto de Ruta Turística, varía según el país y el contexto turístico donde se desarrolle. Investigadores como: Pérez Porto y Merino (2016) exponen que es el camino o recorrido que se destaca por sus atractivos para el desarrollo del turismo. Estas rutas pueden sobresalir por sus características naturales o por permitir el acceso a un patrimonio cultural o histórico de importancia. Así mismo, suele denominarse como ruta turística, de este modo, a aquella vía que sobresale por estar rodeada de lugares que se consideran, por algún motivo, valiosos. Así se espera que los viajeros recorran la ruta turística para conocer sitios de importancia natural, religiosa, cultural, entre otros elementos.

En Argentina de acuerdo al Tesauro Turístico de la Secretaría de Turismo (Forneris, 2014), la ruta turística: se determina estudiando sobre el mapa un itinerario que comprenda la visita de varias localidades de interés turístico. Hay que tener en cuenta los lugares de salida y llegada, de paradas, distancias, comunicaciones, inclusión de valores históricos, paisajísticos, folklóricos.

La contemporaneidad se caracteriza por una gran competencia en todos los mercados y en especial el mercado turístico, debido entre otras causas a la globalización en todos sus niveles. La innovación y la calidad de los productos debe ser una constante, por lo que la creación de una ruta puede significar el inicio de una nueva visión en el futuro del turismo que se desea en una determinada región (Ibarra-Michel y Velarde, 2016)

Para comprender la realidad del turismo se requiere de un enfoque teórico y práctico que permita un acercamiento al entorno, a los destinos. Una de las complejidades del turismo radica en sus diversas manifestaciones, entre las que se destacan, sol y playa, cultural, patrimonial, congresos y convenciones, crucero, deportivo, naturaleza, negocios, aventura, cruceros, náutico, religioso, entre otras. Lo interesante es la ascendente atracción por las experiencias novedosas.

La ruta turística en sí, no sólo implican la visita a lugares predeterminados, sino que involucra todos los productos y servicios adicionales que el visitante requiere, tales como hospedaje, alimentación, transporte, compras de artesanías y recuerdos, guías especializados, entre otros elementos (Ausina, 2014). Facilitan el desarrollo de regiones, que a veces quedan alejadas de un turismo más convencional, además de ser una oportunidad para diferenciarse y atraer a nuevos visitantes.

De igual forma existen varias tipologías de rutas turísticas, no obstantes el resumen planteado por Hernández, J. (2011), es considerado por el autor de la presente investigación el más completo; al plantear que existen tipos y subtipos de rutas turísticas.

En este sentido, la ruta turística por el legado africano de Yaguajay; es del tipo; especifica patrimonial y del subtipo, patrimonio histórico y arqueológico y caminos históricos e itinerarios culturales. Toda Ruta debe adecuarse a un espacio geográfico determinado y estrechamente 


\section{AMAZđ̛́NAS}

relacionado culturalmente; además de establecer recorridos objetivos y razonables. Paralelo a ello se necesitan una serie de indicadores para poder realizar un diagnóstico acertado en relación a la creación de una determinada ruta.

\section{Metodología}

Para realizar el diseño de una ruta turística, la mayoría de los especialistas se basan en metodologías que analizan el contexto geográfico, sociodemográfico, económico, político y cultural de un determinado territorio; además se apoyan en estudios de mercado para tener noción del itinerario turístico de su país, región o zona. Por otro lado, valoran mapas temáticos y regionales, datos estadísticos, análisis de fortalezas, oportunidades, debilidades y amenazas (FODA), entre otros.

Investigadores e instituciones relacionadas con el tema, dígase: Méndez, E. O., y Szmulewicz, P. (1999); Bigné, J, Font, X y Andreu, L (2000); Boullón, R. C. (2006); Arredondo (2013), Ochoa, (2013); Rodríguez, (2019). UNESCO (2019); Sánchez, et.al. (2020) plantean que el diseño de una ruta turística, sobre cualquier tema, debe acoger indicadores como:

- Ubicar y delimitar el territorio, lugar apropiado para instalar la ruta.

- Identificar potenciales actores y realizar un inventario de los recursos del lugar.

- Definir el largo del recorrido y selección del contenido de la ruta (puntos de interés, tiempo con que cuentan los visitantes para el recorrido, discurso enriquecedor que se dará en el transcurso de la ruta)

- Definir los servicios a brindar y capacitación de prestadores de servicios turísticos (guías, entre otros).

- Valorar las estrategias mercadológicas para posicionar la ruta. (Fórmula, turismo vs conservación. Orientación turística)

- Otros servicios adicionales.

- Diseño de la ruta: hacer mapas que permitan visualizar el recorrido, establecer las dimensiones de la ruta, trazar el recorrido, diseño de atractivos y plan del itinerario.

- Establecer el consejo evaluador de la ruta.

Como se ha podido comprender, muchos autores vinculados a temas turísticos, específicamente al diseño de rutas en este sentido, convergen en la implementación de varios indicadores y pasos. No obstante, la presente investigación se acoge a la propuesta planteada por Szmulewicz, P. y Veloso, K (2013), al ser considerada después del análisis, la más objetiva para el diseño de la ruta turística por el legado africano de Yaguajay. Szmulewicz, P y Veloso, K (2013), determina tres etapas para el desarrollo de una ruta turística; las que deben pasar por tres fases:

\section{Fase 1. Determinación de los Objetivos}

- Determinación temática: puede ser general o específica, entregando orientaciones para delimitar el área geográfica, los centros de base y atractivos del recorrido de la ruta.

- Definición de estructura: se debe indicar la duración estimada, la zona a recorrer, actividades a desarrollar, tipo y nivel de servicios de alojamiento, alimentación y transporte requerido, servicios complementarios, excursiones, tiempo disponible y grupo de pasajeros.

\section{Fase 2. Diagramación}

- Relevamiento del área: enunciamiento del circuito, conocimiento histórico, cultural y geográfico del área de estudio. Determinación de atractivos a incluir de acuerdo con la 
distancia desde el centro base más cercana y atractivos previamente seleccionados considerando la accesibilidad.

\section{Fase 3. Diseño de la Ruta}

- Estructuración del itinerario: bosquejo de la ruta; define tiempos en ruta, tiempo de visita, tiempo libre, paradas. Atractivos propios de la ruta.

- Redacción del itinerario: traspaso a papel de los antecedentes recopilados previamente.

Los métodos de nivel empírico ayudaron a la recopilación y procesamiento de la información precisa para cumplir los objetivos de la investigación. Los métodos utilizados fueron los siguientes:

Análisis de documentos: ha permitido sistematizar los documentos relacionados con el patrimonio histórico-cultural y legado africano, dígase los libros objeto de análisis historiográficos, así como, algunas fuentes secundarias que se referencian en el cuerpo de la tesis. Como parte de este método se ha utilizado la técnica análisis de contenido, lo que favorece la orientación de la investigación. Permite la obtención de datos relevantes sobre la evolución del legado africano yaguajayense y su registro en la memoria que se presenta, como parte de una ruta turística.

Entrevista semiestructurada: se ha logrado un intercambio cara a cara entre el investigador y actores claves vinculados al objeto de estudio. Al tener elaborado solo puntos o temas de guía, se emplean preguntas abiertas, lo que ha favorecido respuestas espontáneas y ricas en información. De igual forma, se han realizado a practicantes de las religiones afro en Yaguajay para comprobar testimonios anteriores y a decisores del municipio vinculados al desarrollo local. Se ha recurrido a una información conocida por el investigador para poder ampliarla, comparar criterios, precisar ideas y localizar nuevos datos.

Observación participante: mediante la participación en varias expediciones, eventos científicos, charlas informales, debates, actividades y prácticas religiosas; se ha recopilado información primaria desde el contacto directo con el legado africano en Yaguajay y estudiosos del patrimonio histórico-cultural vinculado al desarrollo local. Ha contribuido a elaborar un registro consecuente del proceso evolutivo del legado africano de Yaguajay, principalmente su itinerario actual.

Encuesta: permitió un análisis crítico direccionado a la propuesta de ruta por parte de siete especialistas que fueron escogidos para valorar el diseño de ruta a partir de sus criterios. Permitió una combinación de respuestas y criterios que resultaron de favorables y la incorporación en el informe final de algunas sugerencias resultantes de la encuesta.

Como parte de los métodos empíricos el trabajo con las fuentes orales ha permitido ver en qué medida la memoria del legado africano en Yaguajay es un elemento a considerar en su evolución y en el estudio. La relación entre el investigador y los testigos lleva aparejada la utilización de las fuentes orales como un recurso relevante en el proceso investigativo. Su utilización condiciona un fuerte trabajo de triangulación, o, los testigos pueden condicionar tu estudio.

También ha contribuido al desarrollo de la exploración el uso de las fuentes iconográficas, las que reflejan directamente la naturaleza y relación social del legado africano con las diversas comunidades donde este se encuentra y se manifiesta. Además, permiten captar en imagen la realidad objetiva, cuestión que no brinda otras fuentes. 
El método cartográfico ha propiciado el análisis crítico a los diferentes mapas antiguos relacionados al proceso de desarrollo azucarero en el territorio y a las propuestas realizadas bajo soporte del Sistema de Información Geográfica (SIG), específicamente la de la autora Borroto Escuela (2017). De igual forma aportó las herramientas para crear en el SIG QGIS 3.0 el mapa de la ruta turística por el legado africano de Yaguajay.

Criterios de especialistas: Se utilizó en la validación práctica de la propuesta de diseño de la ruta turística por el legado africano en Yaguajay.

Triangulación de fuentes: por la diversidad de fuentes y métodos desarrollados, se ha adoptado la triangulación de fuente para lograr una veracidad científica en la investigación. Al constituir un estudio que transita y analiza desde: documentos y mapas antiguos, testimonios; entre otras fuentes de carácter histórico vinculados al tema africano en Cuba, hasta el legado actual del referido tema; resulta complejo y se necesita triangular la información que se sustrae de cada fuente con las demás.

La aplicación de las tres etapas y los referidos métodos, guiaron de manera objetiva la construcción de la investigación. Propiciaron llegar satisfactoriamente al análisis y procesamiento de la información, donde se presentan los resultados obtenidos durante todo el proceso investigativo. De igual forma se pudo identificar el universo que englobaría el estudio, escogiéndose la totalidad de personas que habitan el municipio de Yaguajay (56 685), al constituir estas, activos directos e indirectos de la ruta turística a proponer.

Con respecto a este universo, se identificaron personas y comunidade ${ }^{24}$ conocedoras del objeto y campo de investigación. Específicamente se centró la identificación en los lugares donde se evidencia el legado africano, tanto de manera material como inmaterial. En este sentido, la población quedó conformada por 254 personas de las comunidades Narcisa, Barrio La Loma y Sansaricq en la Cabecera Municipal y Vitoria; zonas por donde transita la ruta turística a diseñar. Fueron seleccionadas 53 personas, las que formaron parte de un muestreo no probabilístico de tipo intencional. Las mismas, constituyen razón insoslayable en los temas relacionados al negro esclavo, patrimonio histórico-cultural, así como turismo y desarrollo local. Además de ser escogidas por su disposición a ayudar con la presente investigación.

\section{Resultados y Discusión}

\section{Análisis estratégico del legado africano Yaguajayense en favor de la ruta turística a proponer}

Alonso et al. (Citado por Díaz, 2017)

En los últimos años, el turismo ha venido diversificándose, ha direccionado su mirada a una búsqueda más equitativa y noble, sin dejar de aportar sus tradicionales ganancias. Los recursos patrimoniales y naturales son vías recurrentes y capaces de transformarse en productos turísticos. Por su lado, las rutas turísticas se han posicionado en el mercado, entre otras causas, por todos los componentes que subyacen en su conceptualización.

El patrimonio histórico-cultural puede dinamizar posibles rutas turísticas en cualquier región, país, territorio o zona, siempre que muestre alguna señal del referido patrimonio. Todo lugar, cuenta con bienes tangibles e intangibles que pueden ser valorados a favor de un turismo

\footnotetext{
${ }^{24}$ Entiéndase por comunidad: "es más que un espacio físico donde ocurren procesos, es la relación social en que la simetría social del vínculo existente entre los sujetos implicados permite señalar la esencialidad que la identifica y la ideología de su devenir". Alonso et al. (Citado por Díaz, 2017)
} 
menos dañino para los ecosistemas; presupuesto que ha tomado impulso necesario a nivel internacional. Cuba como país subdesarrollado han buscado en este patrimonio propuestas de desarrollo y el legado africano de Yaguajay, es una de dichas ofertas.

En el presente epígrafe, se expondrá, de manera objetiva, viable y estratégica, las posibilidades y limitaciones que ofrece el legado africano de Yaguajay, en favor del diseño de una ruta turística por el mismo. Se les realizará el análisis a los componentes identificados mediante el trabajo de campo, análisis documental y bibliográfico y la prospección arqueológica.

En este sentido, las principales debilidades emanadas sobre el legado africano inmaterial fueron:

- Dispersión territorial de las personas que practican cultos o ritos de las religiones afrocubanas.

- Las prácticas y tradiciones culturales, relacionadas a los cultos religiosos, dígase: bembés o toque de tambor, el ritual oricha, danza del palo, la santería, el baile de la botella, el baile del cómo no, los bailes orichas y el ritual de la ceiba; entre otras; atrayentes de gran cantidad de personas, se realizan muchas veces en pequeños grupos por lo que no alcanzan significación social, aunque se está trabajando para llegar al ámbito popular de manera reconocida.

- La mayoría de los niños y jóvenes de Yaguajay, grupos etarios de consideración obligatoria para la preservación de tradiciones culturales, se encuentran desentendidos de las prácticas africanas, entes del acervo cultural del municipio. Existen otras rutinas que son preferidas por estos grupos.

- El movimiento de grupos y artistas aficionados, establecidos en la década del 80 y primeros años de la 90 del siglo pasado, se percibió afectado por el llamado período especial. A partir de entonces se han acometidos varias acciones para revitalizar las tradiciones afrocubanas en Yaguajay, las que todavía no han podido en su plenitud, lograr su objetivo.

- Falta de infraestructuras institucionales que promuevan y alberguen actividades vinculadas al desarrollo y salvaguarda del legado africano inmaterial de Yaguajay; así como la ausencia de sistematicidad de las ya existentes.

Como fortalezas, afloraron:

- Existencia de prácticas y tradiciones afrocubanas en todo el territorio de Yaguajay.

- Identificadas las principales raíces tradicionales, aunque existen otras. Se destacan: bembés o toque de tambor, el ritual oricha, danza del palo, la santería, el baile de la botella, el baile del cómo no, los bailes orichas y el ritual de la ceiba.

- Presencia de personas experimentadas, que, en su cotidianidad, ejercen cultos, ritos y tradiciones africanas locales, como parte de sus sabidurías; las que cultivan y trasmiten a generaciones.

- Reservorio cultural africano en el barrio África de la cabecera

- Sensibilización por parte de los principales actores culturales y gubernamentales de Yaguajay, de la importancia sociocultural que brinda al desarrollo local y comunitario el legado africano inmaterial del territorio.

- Aceptación por parte de la mayoría de los devotos; para que las raíces religiosas afrocubanas locales, sean utilizadas en favor del desarrollo local del municipio; siempre y cuanto se respeten, sea consecuente y no se tergiversen las esencias de las referidas tradiciones.

Las debilidades del legado africano material, lo constituyen, la relación entre razones antrópicas y naturales. Las principales fueron:

- Falta del sentido de pertenencia y en algunos casos desconocimiento subjetivo, por parte de las comunidades, personas y organismos institucionales que poseen bajo su jurisdicción algunos componentes de este legado. 


\section{AMAZÓNAS}

- Profundo y paulatino deterioro de las infraestructuras constructivas pertenecientes a los antiguos trapiches e ingenios del siglo XIX principalmente. Construcciones realizadas en su mayoría por esclavos africanos y parte de sus vidas cotidianas. Se comprobó que la mayoría están en ruinas y en algunos casos falta de mantenimiento.

- Ínfima publicidad de los atractivos y valores turísticos del legado africano material yaguajayense. La divulgación del referido legado se queda en espacios académicos.

Como fortalezas que pueden contribuir al desarrollo de una ruta turística por el legado africano material, fueron consideradas:

- Existencia en todo el territorio municipal de componentes evidentes del referido legado. En algunos casos se encuentran parcial o medianamente conservados.

- Identificación de los principales espacios donde ha existido presencia africana.

- Existencia práctica y en buen estado de conservación de la antigua casa del capitán Don Eduardo Sansaricq, actual Museo General Municipal del territorio. El mismo, constituye, institución referencia que cultiva, trasmite y muestra elementos del legado africano yaguajayense como parte de la historia de la localidad.

- Se cuenta con capital humano preparado e instituciones que investigan el tema afrocubano. Ejemplo fehaciente de ello, es el propio Museo General, la Casa de la Cultura Municipal, el Parque Nacional Caguanes y el Departamento de Estudios Arqueológicos y Paleontológicos, este último posee en sus colecciones piezas arqueológicas pertenecientes a esclavos africanos.

- Parte de la población de las comunidades Narcisa y Vitoria, principalmente, están comprometidas en favor de la utilización de las evidencias materiales del legado africano, como vías para desarrollar el turismo en sus zonas. Comprenden el valor que poseen en este sentido y se manifiestan en contra de su inoperancia y deterioro.

- El municipio es poseedor de una posición geográfica privilegiada, al ubicarse entre dos polos turísticos de significación nacional: Cayo Santa María y Cayo Coco. Cuenta con una red de hospedaje, entre los que resalta la Villa San José del Lago y algunas casas de rentas del sector no estatal. De igual forma posee una empresa de Comercio y Gastronomía, que ostenta varios restaurantes.

- El municipio, desde hace años atrás, experimenta la visita de turismo tránsito, nacional e internacional, a zonas turísticas manejadas por la empresa provincial Flora y Fauna, el Parque Nacional Caguanes y una práctica rural en la comunidad de la Picadora. Es decir, Yaguajay tiene experiencia en diversas modalidades de ejercer el turismo.

La caracterización del legado africano como ente del patrimonio histórico-cultural de Yaguajay, a partir de la identificación de los componentes materiales e inmateriales mediante el estudio realizado, evidenció la posibilidad, uso y manejo del mismo como atractivo turístico. El diagnóstico estratégico efectuado, demostró que este patrimonio está en condiciones que comprometen su conservación, tanto material, como inmaterial, por lo que se propone como vía para su regeneración y sustentabilidad, la creación de una ruta turística por los espacios que albergan elementos en este sentido.

Se patentiza como premisa, que la falta de voluntad política y sentido de pertenencia con respecto a este legado, pueden ser indicadores negativos con relación al objetivo general. No obstante, el municipio tiene condiciones que pueden incidir favorablemente, como su capital humano y fuerza de trabajo, recursos históricos, culturales, naturales, experiencia en asumir procesos de desarrollo local, entre otros. 


\section{AMAZỚNAS}

\section{Diseño y estructuración de la ruta turística por el Legado Africano de Yaguajay}

\section{Determinación de objetivos}

En el presente epígrafe se desarrollará la primera etapa de la metodología adoptada para el diseño de la ruta a proponer. Se partirá de la determinación temática y definición de la estructura. Para la mejor comprensión y claridad del capítulo, se dividirán en subepígrafes, las fases que guían los pasos para el diseño de la ruta turística por el legado africano de Yaguajay.

\section{Temática de la Ruta}

Se proyecta desarrollar una ruta que tiene como temática principal el desarrollo de actividades de turismo histórico-cultural, vinculadas al patrimonio tangible e intangible que subyace en la Yaguajay actual y tuvo su desarrollo en el siglo XIX. El nombre propuesto para esta ruta es "Ruta turística por el legado africano de Yaguajay", siendo este, ente indispensable del patrimonio histórico-cultural del territorio y poseedor de componentes y atractivos tangibles e intangibles en este sentido.

La presencia de ruinas e infraestructuras de los antiguos trapiches e ingenios del territorio; evidencias arqueológicas, representadas por prendas y utensilios relacionados a la cotidianidad del africano, las que muchas veces se pueden encontrar como bienes muebles y las tradiciones culturales afrocubanas, expresadas en prácticas religiosas y actividades relacionadas e estas; constituyen centro de atención de la ruta. De igual forma, se vinculan a los prestadores de servicios estatales y no estatales.

La Empresa Municipal de Comercio y Gastronomía con sus unidades de venta de comidas y bebidas; restaurantes; propietarios de paladares, bares, cafeterías y arrendadores de viviendas, habitaciones y espacios; constituyen parte de los operadores locales que se integrarían e impulsarían la ruta a desarrollar. Cabe recalcar que se realizarán actividades complementarias en apoyo a la ruta, enfocadas en la visita a museos, observación de flora y fauna presente durante el recorrido, bienes muebles evidenciables en los inmuebles; entro otras.

\section{Tipología de ruta}

La ruta se inserta en los sistemas de ruta turística temporal y temática. Por un lado, la primera, se lleva a cabo en un espacio geográfico determinado, donde el desplazamiento está focalizado en un hecho o fenómeno y la segunda, se enfoca en un tema, el cual puede ser étnico, etnográfico, cultural, natural, científico, entre otros. La presente complementa estas dos líneas, aunque se inclina por la temporal.

Se propone que la ruta sea guiada por agentes locales, los cuales deben tener inicialmente una formación y capacitación con el fin de ofrecer servicios de calidad. El desplazamiento se complementará con material promocional que oriente sobre los distintos atractivos y las actividades que se desarrollan en la ruta. Es necesario un centro de información y acogida al turista al inicio, con el fin de orientar e informar al visitante sobre la misma, así como también la instalación de señalizaciones y paneles informativos en la ruta que sirvan de guía.

\section{Área geográfica general}

La ruta se despliega por zonas de las comunidades de Narcisa, Vitoria y la Cabecera Municipal, áreas que constituyen el campo de acción. Cubre una superficie aproximada de 22 kilómetros, en la cual se abarcan todos los principales atractivos históricos y culturales representativos del legado africano material e inmaterial. Se tuvo en cuenta que las áreas fuesen 


\section{AMAZÓNAS}

capaces de sustentar la visita de turistas, excursionistas y viajeros que pretendan conocer la ruta sin que esto represente una amenaza tanto para los destinos receptores ni para los visitantes, así mismo, ubicación geográfica (colindantes) y la ínfima distorsión de la desviación en su principal vía de comunicación (carretera) entre puntos a visitar.

En sentido general, parte de la superficie geográfica de las áreas objeto de la ruta a desarrollar, constituyeron hasta principios de los años 2000, zonas económicas de producción azucarera. La vida se desarrollaba al calor de la caña y los centrales Obdulio Morales y Simón Bolívar, conocidos como Narcisa y Vitoria respectivamente. El cierre de los mismos, constituyó un golpe en la cotidianidad de la población y un cambio en la estructura geográfica productiva. El despliegue de la ruta por estos espacios y su vinculación a elementos complementarios, pudiera ser una inyección revitalizadora para estas comunidades.

\section{Centro base de la Ruta Turística}

En un primer momento, la ruta sería concebida para clientes que visitan Cayo Santa María o Cayo Coco, zonas turísticas cercanas a Yaguajay y propicias para comercializar la ruta propuesta. Así mismo, pudieran ser posibles interesados, personas de paso por el territorio, que después de observar los carteles informativos sobre la ruta, ubicados en las tres entradas al municipio vía terrestre; se interesen por el recorrido.

Desde este enfoque, el centro base de la ruta sería el establecimiento de Rent a Card, ubicado en la salida este de la cabecera municipal. Se propone, el mismo por las facilidades de transporte cuatro por cuatro que ofrece, además de tener experiencias en actividades parecidas. Rent a Card de Yaguajay, es parte en la actualidad de dos productos turísticos ofertado en los hoteles de Cayo Santamaría: "Mar y Tierra" y "Safari Jobo Rosado". Este centro base, constituiría punto de partida de la ruta y por ende se le daría al cliente las primeras explicaciones que lo ubiquen en la actividad que realizará.

Se recomienda sea siempre una excursión grupal, respetando la capacidad de carga de los inmuebles a visitar

\section{Periodo de funcionamiento de la ruta}

La ruta turística por el legado africano de Yaguajay, está proyectada a funcionar todos los meses del año, pues el recorrido sería por bienes inmuebles y los lugares complementarios a visitar ofrecen servicio al público todo el año. Se reforzarán las condiciones, en los meses de noviembre a mayo, período donde se afianza la temporada alta del turismo en Cuba.

\section{Diseño de la ruta turística}

En este epígrafe se pretende brindar un procedimiento con carácter estructural, participativo, flexible y dinámico, para el diseño de la ruta turística por el legado africano de Yaguajay, adaptada a las condiciones reales del territorio en este sentido. Tiene en consideración; no solo; las interacciones que subyacen en el interior de la ruta en sí, sino también, la relación con los principales destinos turísticos cercanos. Permitirá el desarrollo de estos y del territorio yaguajayense, bajo las nuevas necesidades del mercado turístico actual y las características de la gestión de productos turísticos emergentes.

Se traza una táctica basada en cuatro puntos, los que se expondrán a continuación; para lograr incorporar la ruta a las ofertas turísticas del municipio y del país. Toma como base una serie de recursos históricos y culturales vinculados a las evidencias materiales e inmateriales del legado africano; así como una serie de actividades complementarias, que podrían incorporarse, 


\section{AMAZÓNAS}

sin perder la esencia de la visita del cliente y constituye una experiencia a vivir más que un simple viaje contemplativo.

\section{Mapa de la Ruta Turística}

La siguiente proyección cartográfica indica el recorrido total que se realiza en la ruta, abarcando los atractivos centrales e incluyendo en ella, las distintas actividades complementarias que se llevarán a cabo.

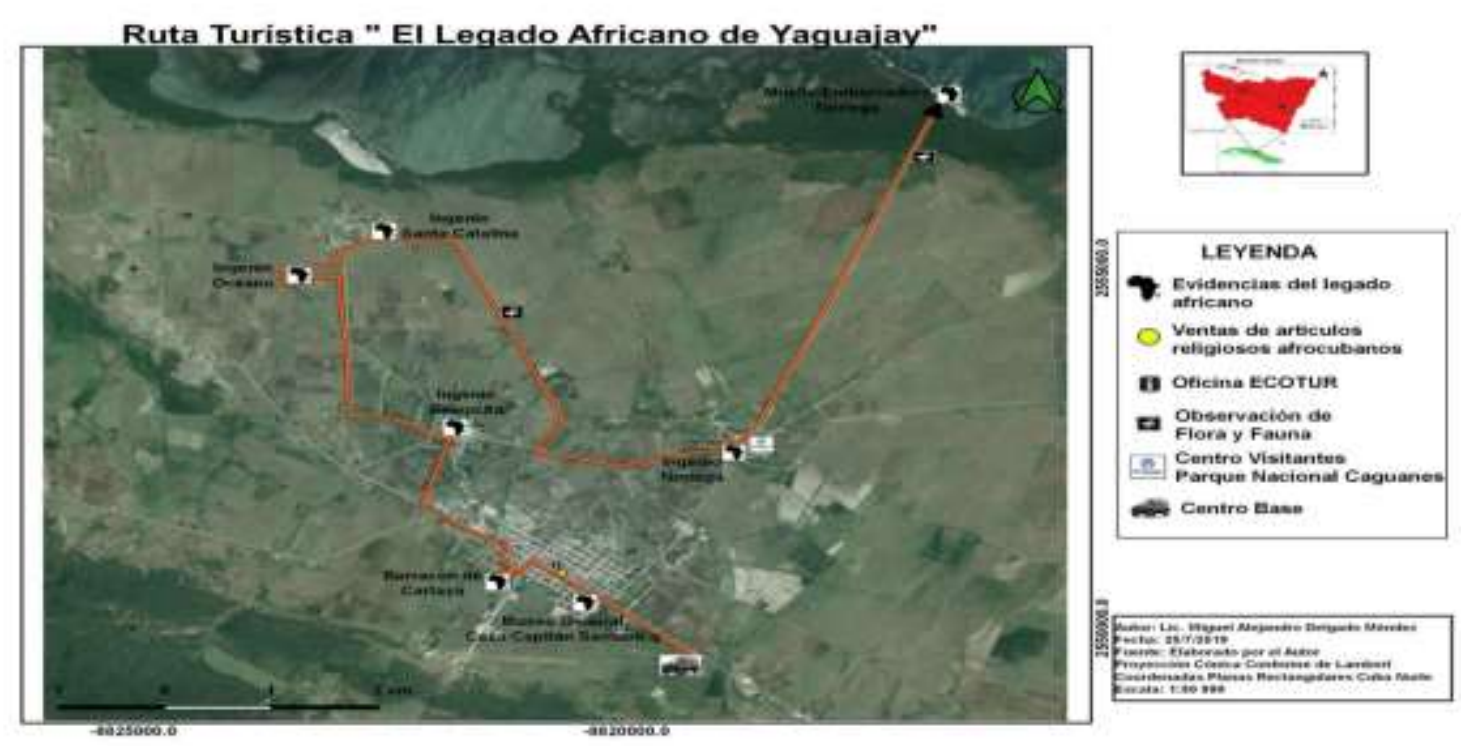

Figura 1. Ruta Turística "El legado africano de Yaguajay".

El diseño de la Ruta Turística por el legado africano de Yaguajay, se enfoca principalmente, en brindar, a la vista del cliente las principales evidencias materiales e inmateriales de este patrimonio histórico-cultural.

\section{Oferta de actividades complementarias en la ruta turística}

En el recuadro se señalan las actividades que se pueden llevar a cabo dentro de la ruta con su respectiva descripción. El guía le entregará un documento impreso con el recuadro resumen y el grupo, escogerá de forma optativa, las actividades a realizar; siempre se negociará para que no sean más de tres, principalmente en aras del tiempo. No obstante, el guía y el tour líder o la persona que venga al frente del grupo, de previo y mutuo convenio, determinarán la opción; según las características grupales y conocimiento del guía sobre las actividades.

Toda actividad es flexible a cualquier movimiento e incluso se puede elegir no realizar ninguna o una sola; en caso, por ejemplo, que el tiempo que posee el grupo en el día, sea reducido y alcanza solo para visitar los atractivos históricos-culturales referidos en el recuadro.

\section{Servicios incluidos en la ruta turística}

En la actividad turística existen diversos servicios que son esenciales para la vida de este proceso, como actividad y como fenómeno social, de esos servicios, los básicos son: el hospedaje, la alimentación y el transporte. Estas tres clases de servicios son las obligatorias mínimas para brindar al turista la seguridad que requiere al verse envuelto en un entorno social 


\section{AMAZÚNAS}

distinto al habitual; partiendo del cumplimiento de éstos se puede considerar un destino apto en servicios para la actividad turística (Arredondo, 2013).

Los servicios a los que se hace alusión existen en la actualidad asociados a establecimientos e instituciones, estatales como no estatales, que brindan servicios en Yaguajay.

De igual forma, el visitante, escoge la opción con la que se sienta más cómodo y también su disponibilidad. Se incorpora, como servicio necesario, siempre y cuando se realice la ruta en los autos que ofrece Rent a Card municipal; la colocación de un sistema de audio para cada carro, los que estarán conectados entre sí, por el cual, el guía, desde su posición, brinda información adyacente durante el recorrido.

\section{Propuesta de empaquetamiento}

Esta ruta se desarrolla en una sola zona geográfica; Yaguajay, por lo tanto, se propone un paquete turístico de un día, que permita recorrer los principales atractivos históricos-culturales del legado africano con detenimiento, integrando actividades y servicios locales en su realización. Se propone, pueda ser atractiva para los visitantes y ser acogida por la comunidad debido a que se involucran en la prestación de distintos servicios.

Es necesario recalcar, que la propuesta de empaquetamiento (tabla1) parte de una idea inicial para un día; no obstante; durante el proceso evolutivo de la ruta puede adoptar de uno a tres días. Según, las potencialidades identificadas del legado africano en Yaguajay; el trabajo para revertir en fortalezas, algunas de sus debilidades y la propuesta, de otros atractivos históricosculturales; así como, la incorporación de nuevas actividades y servicios locales; sería práctico y viable la incorporación de más días.

Los horarios establecidos para la propuesta de empaquetamiento, fueron resultados de una prueba de campo realizada por el autor, choferes y el representante de gaviota tour por Rent a Card de Yaguajay. Se recorrieron todos los puntos que se representarán en el mapa de la ruta turística, teniendo en cuenta descripción de los atractivos, velocidad establecida para zonas urbanas y rurales según tránsito; así como; experiencias de velocidad promedio con que se realiza los dos productos turísticos que involucra a Rent a Card de Yaguajay.

Propuesta de empaquetamiento de la Ruta Turística.

Tabla 1.

La propuesta de empaquetamiento.

\begin{tabular}{|c|c|}
\hline \multicolumn{2}{|l|}{ Ruta Turística por el Legado Africano de Yaguajay } \\
\hline Unico Día \\
\hline Carácter: Cultura e historia \\
\hline Dificultad: moderada \\
\hline \multicolumn{2}{|c|}{ Attinerario } \\
\hline Hora & \multicolumn{1}{c|}{ Actividades y Descripción } \\
\hline $\mathbf{8 . 3 0}$ am & $\begin{array}{l}\text { Bienvenida al centro base y encuentro con el guía local. El mismo le explicará } \\
\text { brevemente en que consiste la ruta y le entregará al tour líder las actividades } \\
\text { complementarias a realizar y servicios locales de refrigerio y almuerzo. }\end{array}$ \\
\hline $\mathbf{8 . 3 5}$ am & $\begin{array}{l}\text { Después de definir: actividades complementarias a realizar y servicios locales } \\
\text { de refrigerio y almuerzo; se partirá hacia el primer punto de interpretación } \\
\text { (Museo General Casa Capitán Sansaricq) }\end{array}$ \\
\hline
\end{tabular}




\begin{tabular}{|c|c|}
\hline $8.36 \mathrm{am}$ & $\begin{array}{l}\text { Arribo a la Casa Capitán Sansaricq. Se les comunica que es el actual Museo } \\
\text { General del municipio y se les brinda el recorrido por el mismo direccionado a } \\
\text { la historia del lugar y su relación con el legado africano. De igual forma se les } \\
\text { comenta que están cerca del antiguo cabildo de Yaguajay, ubicado en el Barrio } \\
\text { África. Se realiza en el museo, una actividad cultural sobre las tradiciones } \\
\text { afrocubanas en el territorio. }\end{array}$ \\
\hline $9.30 \mathrm{am}$ & Salida hacia el Paseo Agramontés. \\
\hline $9.31 \mathrm{am}$ & $\begin{array}{l}\text { Conocido como el Boulevard de Yaguajay; los visitantes podrán compran } \\
\text { opcionalmente prendas manufacturadas identitarias de las tradiciones } \\
\text { afrocubanas, entre otros elementos, que se venden en el paseo. De igual forma } \\
\text { podrán dar un breve recorrido por el centro de la Cabecera Municipal y percibir } \\
\text { parte de la cotidianidad del yaguajayense y visitantes. }\end{array}$ \\
\hline 9. $51 \mathrm{am}$ & $\begin{array}{l}\text { Salida hacia el segundo punto de interpretación (Barracón de esclavos del } \\
\text { Ingenio Encarnación, también conocido como Cartaya) }\end{array}$ \\
\hline $9.55 \mathrm{am}$ & $\begin{array}{l}\text { Arribo al barracón. Se les muestra el grado de conservación del mismo y se les } \\
\text { comenta brevemente su itinerario histórico. Se visita la propiedad ubicada al sur } \\
\text { del barracón; zona real donde se encontraba el ingenio y se evidencia el pozo } \\
\text { con su noria. }\end{array}$ \\
\hline $10.25 \mathrm{am}$ & $\begin{array}{l}\text { Salida hacia el tercer punto de interpretación. (Ingenio Belencita-Narcisa) } \\
\text { Durante este recorrido, se toma la entrada a Narcisa por el reparto petrocasas } \\
\text { "Cuatro de Abril" y por el dispositivo de audio ubicado en todos los carros, el } \\
\text { guía, le comenta; llegado el momento y con una breve parada, sin bajar del carro; } \\
\text { que a sus izquierdas se encuentra el poblado de Camaján; zona donde se ubicó } \\
\text { el primer trapiche de la zona; nombrado por su dueño Don Diego de la Coloma } \\
\text { como: Sabanas de Camaján o Yaguajay. }\end{array}$ \\
\hline 10.38 am & $\begin{array}{l}\text { Llegada a la zona que ocupaba el ingenio. Se muestra la antigua torre de } \\
\text { ladrillos, elemento con mayor grado de conservación del Belencita. Como } \\
\text { atractivo complementario, se les enseña, los obeliscos en honor al lugar, donde, } \\
\text { terminó la Guerra Necesaria Máximo Gómez y se construyó el Dragón Número } \\
\text { 1, por órdenes de Camilo, durante la batalla de Yaguajay, respectivamente. Con } \\
\text { previo acuerdo, el refrigerio se encuentra en el Bar Colonial. Se toma el } \\
\text { refrigerio y se les explica, que están degustando, en lo que fuera el antiguo } \\
\text { barracón de esclavo del ingenio; además de otras explicaciones relacionadas: } \\
\text { evolución y actualidad del barracón. }\end{array}$ \\
\hline 11.20 am & $\begin{array}{l}\text { Concluido el refrigerio, salida hacia el cuarto punto de interpretación (Ingenio } \\
\text { Océano). }\end{array}$ \\
\hline 11.30 am & $\begin{array}{l}\text { Arribo a la zona donde se encontraba el ingenio. Observación del pozo original } \\
\text { con su noria; parte de las infraestructuras, envase de agua, ruinas de casas de } \\
\text { vivienda, barracón y distorsión en el terreno donde se observa el viradero del } \\
\text { tren. Todo lo anterior complementado por información del guía. Como atractivo } \\
\text { complementario, se le enseña y se le explica un obelisco ubicado en la misma } \\
\text { zona, correspondiente al primer campamento de Máximo Gómez a su llegada al } \\
\text { territorio. }\end{array}$ \\
\hline $11.50 \mathrm{am}$ & Salida hacia el quinto punto de interpretación (Ingenio Santa Catalina). \\
\hline $11.55 \mathrm{am}$ & $\begin{array}{l}\text { Llegada a la zona donde se encontraba el Ingenio. Explicación del guía sobre la } \\
\text { evolución histórica del ingenio; observación panorámica y de evidencias } \\
\text { tangibles, relacionadas al legado africano y proceso de producción azucarera del } \\
\text { ingenio. Se muestran las ruinas de la casa vivienda del dueño del ingenio. } \\
\text { Intercambio de comentario de los visitantes. }\end{array}$ \\
\hline $12.15 \mathrm{pm}$ & $\begin{array}{l}\text { Salida hacia el sexto punto de interpretación (Ingenio Noriega-Vitoria). Durante } \\
\text { este recorrido, se podrá contemplar parte de la flora y fauna cubana; así como; }\end{array}$ \\
\hline
\end{tabular}




\begin{tabular}{|c|c|}
\hline & $\begin{array}{l}\text { algunas especies identitarias de la zona, a través de la observación en la zona } \\
\text { campestre de siempre viva. }\end{array}$ \\
\hline 12.35 pm & $\begin{array}{l}\text { Arribo a zonas donde se encontraba el Ingenio. Se muestran algunas de las } \\
\text { infraestructuras que se conservan: barracón de esclavos (actuales casas de } \\
\text { viviendas), casa de mayorales y del dueño del ingenio; esta última casa de } \\
\text { abuelos de la comunidad. De igual forma, se le muestra al visitante, la campana } \\
\text { con que eran llamados los esclavos al trabajo; así como; las ruinas del almacén } \\
\text { de azúcar. Se explica la evolución y reutilización de estas infraestructuras hasta } \\
\text { la actualidad. }\end{array}$ \\
\hline $1.10 \mathrm{pm}$ & $\begin{array}{l}\text { Llegada al Centro de Visitantes del Parque Nacional Caguanes. Se realizará un } \\
\text { recorrido por el centro, guiado por un especialista de la entidad; donde se les } \\
\text { resumirá, los atractivos históricos-culturales del área protegida. De igual forma, } \\
\text { el visitante vislumbrará que la infraestructura, se encuentra en zonas donde se } \\
\text { encontraba el ingenio. }\end{array}$ \\
\hline $1.20 \mathrm{pm}$ & $\begin{array}{l}\text { Salida hacia el séptimo punto de interpretación (Muelle-Embarcadero Noriega) } \\
\text { Durante el recorrido se pueden observar, especies de flora como el mangle, muy } \\
\text { cerca al embarcadero. }\end{array}$ \\
\hline $1.30 \mathrm{pm}$ & $\begin{array}{l}\text { Arribo al Muelle-Embarcadero Noriega, actual restaurante del Motel Playa } \\
\text { Vitoria. Se les muestra fotos históricas sobre el referido muelle-embarcadero y } \\
\text { una descripción sobre la evolución histórica de la instalación, acompañada de un } \\
\text { breve recorrido. }\end{array}$ \\
\hline $1.45 \mathrm{pm}$ & $\begin{array}{l}\text { Almuerzo en el restaurant. Después, se sale al balcón ubicado a unos tres metros } \\
\text { al norte del restaurant y se realiza una vista panorámica de los cayos de piedras; } \\
\text { ecosistemas cársticos del Parque Nacional Caguanes. En el lugar se realiza un } \\
\text { intercambio retroactivo sobre la ruta turística y se regresa al centro base. }\end{array}$ \\
\hline 2.00 & Regreso al centro base. \\
\hline 2.15 & $\begin{array}{l}\text { Llegada al centro base y fin de la ruta turística por el legado africano de } \\
\text { Yaguajay. }\end{array}$ \\
\hline
\end{tabular}

Fuente: Elaboración propia

Al constituir una propuesta de empaquetamiento; no se incluyeron, tres elementos de los atractivos histórico-culturales de la Ruta Turística por el Legado Africano de Yaguajay, en aras de la mayor objetividad de la propuesta. Pueden ser incorporados, siempre que se cambie uno por uno o que los visitantes; opten por no realizar ninguna actividad complementaria. De igual forma, el itinerario está sujeto a cambios de acuerdo a las condiciones climáticas y físicas del visitante.

\section{Propuesta de operación de la ruta}

Como se ha venido desarrollando en el discurso de la presente investigación, se deja entender, que no existe categóricamente una línea a seguir para el desarrollo y éxito de una ruta turística. Existen varios pasos que, según los investigadores del tema, se deben tomar en cuenta para, garantizar un desarrollo sustentable que; a corto, mediano y largo plazo supongan, la permanencia y evolución de la ruta; así como; un ambiente sensiblemente y mejorado de las condiciones de vida de los habitantes de comunidades y regiones donde se dé el fenómeno turístico.

El éxito de una ruta turística debe basarse también, en el firme progreso de las capacidades y competencias de los participantes, así como, una adecuada elaboración de acciones estratégicas e iniciativas que le permitan ser atrayente en el mercado. De igual forma, debe convertirse en una fuente lucrativa de ingresos para el desarrollo local y en una opción participativa de los habitantes 


\section{AMAZỚNAS}

de las comunidades incluidas en la ruta. En este sentido, se exponen elementos indispensables para la propuesta de operación de la ruta turística por el legado africano de Yaguajay.

\section{Imagen de la ruta turística}

Se propone la creación de un logo (figura 2) para comunicarse con el visitante, de la manera más directa y en menor tiempo posible. Mediante la imagen de la ruta turística, se brindará una información visual, básica y espontánea sobre; el legado africano de Yaguajay. Adaptándose a unos de los principios del diseño, donde "menos es más", se buscará dejar una imagen de marca con nombre a largo plazo.

La imagen turística permitirá el reconocimiento y diferenciación del resto de los productos que se oferten en el territorio; paralelo a ello se pudiera realizar publicidad de la ruta mediante la utilización de la imagen de ruta. En el proceso de desarrollo de la ruta, esta imagen se debe patentizar en la Oficina Cubana de Propiedad Industrial, para lograr un posicionamiento a nivel nacional e internacional. De igual forma, se propone, sean ubicados, tres logos, uno en cada entrada al municipio de Yaguajay.

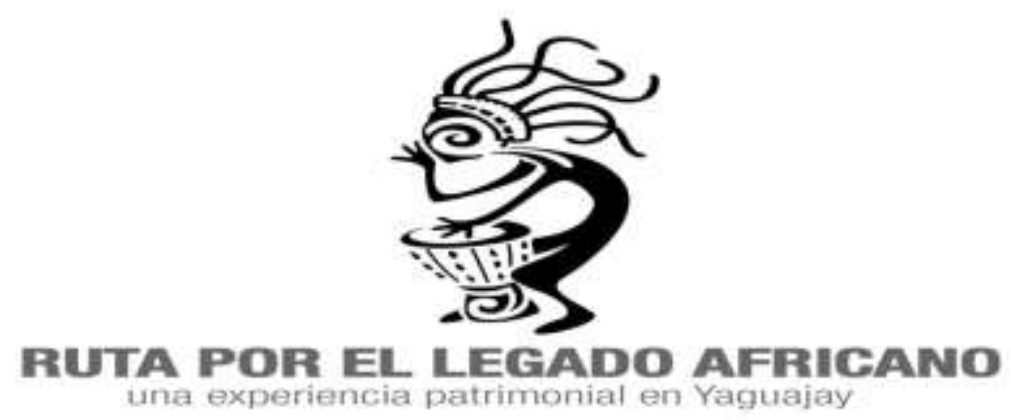

Figura 2. Imagen de la Ruta Turística.

Fuente: Elaborado por el autor

\section{Señalización turística de la ruta}

Para realizar la propuesta de señalización de la ruta por el legado africano en Yaguajay, se adopta lo estipulado en el manual de señalización turística de Colombia, actualizado en el 2015, al constituir este, práctico y viable para el territorio yaguajayense. No obstante, las medidas y material con que se realicen los carteles y paneles, se deben ajustar al contexto actual en que se realicen.

La señalización debe ser concreta y legible, no molestar el ecosistema donde se ubiquen. En el caso, que se coloquen en carretera, deben ajustarse a lo estipulado en el ámbito internacional; de acuerdo con las normas viales; fondo azul con letras blancas en zonas urbanas; fondo carmelita y en algunos casos verdes en zonas rurales y campestre, para así evitar confusión. De conjunto acuerdo con tránsito y viales municipal o provincial, deben determinarse apropiadamente los sitios de ubicación de las señales turísticas en función del mensaje que se quiera transmitir y de las distancias de visibilidad implementadas en Cuba.

La cantidad de señales a clocar, las define, los actores involucrados en la ruta turística; así como; el lugar propicio para instalarlas. En caso, de que alguna señal conlleve leyenda; esta debe ser efímera y clara. 


\section{AmAZÚNAS}

Según las necesidades de la superficie donde se desarrolla la ruta turística; se proponen las siguientes señales:

- Cartel informativo: en las tres entradas a la cabecera municipal. Se pudiera ubicar uno solo en el centro de la localidad, muy cerca del punto de información turística del territorio (Oficina ECOTUR). Contendrá la información que espontánea necesaria para provocarle al visitante curiosidad por la ruta.

- Señales de referencias: se ubicarán en los caminos, carretera o vías de acceso, previo a los atractivos históricos-culturales del legado africano y servicios de la ruta. Informaran acerca del atractivo o servicios a visitar y distancia.

- Monolito: se ubican en la entrada de los espacios a visitar, logrando su identificación y contenido, en cada espacio; puede ser de la siguiente manera:

A - Identificación: se indica el pictograma de información.

B - Localización: se describe la identificación del atractivo turístico.

C - Información de contexto: se ubica la información de texto o imagen complementaria de ser necesario.

D - Información didáctica: sobre cuidados con el patrimonio, la naturaleza, flora y fauna, así como las prohibiciones.

\section{Condiciones para la implementación de la ruta}

La ruta se llevará a cabo todos los meses del año, reforzando el período de temporada alta del turismo en Cuba. El horario para comenzar el recorrido, después de la llegada del grupo a centro base, se extiende desde las 8.35 am hasta las $2.15 \mathrm{pm}$; con el fin de aprovechar la luz solar, además de que está programado para un solo día. Las zonas de prestación de servicios son las enumeradas en la tabla 4; se parte de la actualidad en sus servicios, específicamente las ubicadas en las comunidades involucradas en la ruta (Yaguajay Cabecera, Vitoria y Narcisa).

Con el fin de asegurar la satisfacción de los visitantes, considerando aspectos relativos a la calidad de los recursos y sostenibilidad de los mismos; se requiere, de un estudio de capacidad de carga y de manejo en las áreas más vulnerables de la ruta turística. Siendo este tema, poco tratado por investigadores cubanos, se propone como referente, el estudio local realizado por la autora Hernández Ortiz (2017). La misma en su investigación brinda metodologías para realizar un estudio en este sentido (Hernández, 2017).

\section{Requisitos legales}

Es esencial que todos los actores vinculados a la ruta; dígase: establecimientos y operadores que presten servicios turísticos en la misma, cumplan con los requisitos de legalidad necesarios en Cuba para este fin. Tienen que tener, la documentación requerida al día. Es requisito indispensable:

\section{Capacitación}

El campo de acción de la presente investigación, requiere personas con las competencias y las habilidades requeridas para su participación dentro de la ruta turística por el legado africano de Yaguajay. La preparación de los prestadores de servicios, es fundamental para que la ruta pueda funcionar, debido a que ellos son los que dinamizan la actividad turística; de su capacidad depende en gran medida que el visitante goce de su estancia y genere la satisfacción que se desea, con las implicaciones positivas que esto refleja. 
Si bien, estas líneas de capacitación, no son las únicas, sí brindan una base y panorama general de los aspectos que se deben solucionar como primera necesidad para que el servicio a ofrecer, además de satisfacer, pueda procurar criterios de calidad. En este sentido se establece el siguiente programa de capacitación sistemático:

\section{Plan de promoción y difusión}

Con el objetivo de promocionar la imagen de la ruta y dar a conocer los atractivos históricos-culturales de la misma, así como, las actividades que se pueden llegar a cabo dentro de ella; es necesario presentarla en todos los espacios posibles y que logre ser visible aprovechando su posición y cercanía a industrias turísticas como la zona hotelera de los Cayos Santa María al norte de Villa Clara y Cayo Coco, al norte de Ciego de Ávila. Desde este enfoque, se propone el siguiente plan para su divulgación:

\section{Tabla 2.}

Propuesta de planes de promoción y difusión de la Ruta Turística.

\begin{tabular}{|c|c|c|c|}
\hline $\begin{array}{c}\text { Estrategia de } \\
\text { posicionamiento }\end{array}$ & Plan & Actividad & $\begin{array}{l}\text { Público } \\
\text { Receptor }\end{array}$ \\
\hline $\begin{array}{l}\text { Reuniones } \\
\text { estratégicas }\end{array}$ & $\begin{array}{l}\text { Participación en las reuniones } \\
\text { de la comisión de desarrollo } \\
\text { local; oficina de la agencia } \\
\text { EOTUR municipal, consejos de } \\
\text { seguridad y dentro de las } \\
\text { posibilidades, requiriendo } \\
\text { invitación a las organizadas por } \\
\text { las oficinas de negocios de los } \\
\text { Cayo Santa María y Coco. }\end{array}$ & $\begin{array}{l}\text { Participación en la } \\
\text { mayor cantidad de } \\
\text { reuniones } \\
\text { estratégicas para } \\
\text { establecer posibles } \\
\text { negocios, } \\
\text { promoción, costos; } \\
\text { hasta solicitar apoyo. }\end{array}$ & $\begin{array}{l}\text { Consejo de } \\
\text { administración } \\
\text { municipal, } \\
\text { universidades, } \\
\text { empresas } \\
\text { locales, } \\
\text { accionistas } \\
\text { comunitarios. }\end{array}$ \\
\hline Publicidad & $\begin{array}{l}\text { Presencia sistemática en los } \\
\text { medios de televisión y } \\
\text { comunicación local, provincial } \\
\text { y nacional; este último de } \\
\text { acuerdo a las posibilidades } \\
\text { reales. } \\
\text { Publicidad con puntos } \\
\text { estratégicos; hostales de la } \\
\text { región y centro de información } \\
\text { turística, en el caso de } \\
\text { Yaguajay; la oficina de } \\
\text { ECOTUR. Por la cercanía, } \\
\text { llegar hasta la mesa de negocios } \\
\text { de los Cayos Santa María y } \\
\text { Coco. }\end{array}$ & $\begin{array}{l}\text { Diseño de material } \\
\text { publicitario respecto } \\
\text { a la ruta turística } \\
\text { enfocado a las } \\
\text { nuevas tendencias } \\
\text { del turismo } \\
\text { internacional y local }\end{array}$ & $\begin{array}{l}\text { Turismo } \\
\text { nacional } \\
\text { internacional. }\end{array}$ \\
\hline $\begin{array}{l}\text { Presentaciones } \\
\text { multitudinarias }\end{array}$ & $\begin{array}{l}\text { Participación en eventos de } \\
\text { corte turístico y patrimonial; así } \\
\text { como ferias turísticas. FIART, } \\
\text { TURNAT, entre otras. }\end{array}$ & $\begin{array}{l}\text { Lograr convenios } \text { o } \\
\text { alianzas } \quad \text { con, } \\
\text { instituciones } \\
\text { turísticas, } \\
\text { cooperativas. }\end{array}$ & $\begin{array}{l}\text { Turoperadores, } \\
\text { hoteles y } \\
\text { hostales }\end{array}$ \\
\hline
\end{tabular}




\section{AMAZÖ́NAS}

\begin{tabular}{|l|l|l|l|}
\hline $\begin{array}{l}\text { Valor agregado } \\
\text { y } \\
\text { Sustentabilidad. }\end{array}$ & $\begin{array}{l}\text { Capacitación sistemática a los } \\
\text { prestadores de servicios. }\end{array}$ & $\begin{array}{l}\text { Programas de } \\
\text { capacitación para } \\
\text { mantener la imagen } \\
\text { de la ruta, basados en } \\
\text { temas vinculados a } \\
\text { mercado laboral } \\
\text { para la ruta } \\
\text { turística. }\end{array}$ \\
& $\begin{array}{l}\text { guspedaje, turísticos, } \\
\text { hospen } \\
\text { alimentación, } \\
\text { conservación, entre } \\
\text { otros. }\end{array}$ & \\
\hline
\end{tabular}

Fuente: Elaborado por el autor.

Valoración de la propuesta de diseño de ruta a partir del criterio de especialistas

La valoración del diseño de la ruta turística propuesto, mediante el criterio de especialista, partió de la selección de investigadores y conocedores del patrimonio histórico-cultural, legado africano y sus relaciones con el turismo y el desarrollo local. Constituyeron, profesionales que se desempeñan como especialistas o directivos de instituciones vinculadas a los temas referidos. Los mismos poseen conocimiento profundo y están familiarizados con los puntos abordados en la propuesta de diseño, de manera que en el análisis se incluyen criterios desde puntos de vistas diferentes y son considerados "expertos" a efectos de la presente investigación.

Para aplicar el criterio de especialista como parte de la valoración a una serie elementos de la propuesta, se siguieron los siguientes pasos:

- Identificar los especialistas, teniendo en cuenta: relación con el objeto y campo de investigación, profesionalidad, experiencia, grado de comprometimiento y voluntad política y disposición a cooperar.

- Cuestionario en forma de encuesta, direccionado a elementos de la propuesta de diseño a valorar (diseño de la ruta; propuesta de operación)

- Análisis crítico de las respuestas y opiniones resultantes.

En este sentido, se lograron criterios de: pertinencia, integración, flexibilidad, racionalidad, concepción holística y sistémica, aplicabilidad y viabilidad y factibilidad; los que llevaron a obtener una respuesta por parte de los especialistas que avalaron el diseño propuesto en las condiciones actuales del país y Yaguajay.

Determinación del número de especialistas

Para la determinación del número de especialistas (M) se utilizó la expresión: $\mathrm{Ne}=\mathrm{p}(\mathrm{I}$ -

p) $\mathrm{k}$

Dónde:

Ne: número de especialistas.

I: nivel de precisión que expresa la discrepancia o variabilidad que muestra el grupo en general $(0,005-0,10)$.

p: porcentaje de error que como promedio se tolera en el juicio de los especialistas $(0,01-0,5)$.

k: constante cuyo valor está asociado al nivel de confianza (1- $\alpha)$.

Para el caso de estudio se estableció un nivel de confianza $(1-\alpha)=0,99$ para un valor de la constante $\mathrm{k}=6,6564$, una proporción estimada de error $(\mathrm{p})=0,01$ y un nivel de precisión $(\mathrm{I})=$ 0,10 


\section{AMAZỚNAS}

Como resultado se obtiene: $\mathrm{Ne}=6,589836$

Como resultado final se toman: siete (7) especialistas.

Para la recolección de criterios se utilizó un cuestionario en forma de encuesta que permitió el análisis crítico, coherencia, viabilidad y posible aplicación de la propuesta de diseño de ruta.

Cuando se realizó el procesamiento de los resultados; los encuestados plantearon que la propuesta se ajusta a las necesidades actuales del municipio, en relación a la actividad turística como recurso del desarrollo local, al desarrollo de las comunidades por donde transita la ruta turística, para las instituciones culturales, turísticas y trabajadores por cuenta propia del territorio. Se planteó además que la propuesta contribuye al logro de una mayor organización del sistema de planeación territorial en el municipio Yaguajay al poder lanzarse como una zona estratégica para desarrollar otras variantes de turismo, más allá, de lo tradicional.

Por otro lado, la propuesta de ruta puede ser referente metodológico y aplicable en otros municipios que alberguen componentes del patrimonio histórico-cultural. Dada su flexibilidad, su aplicación permite adecuarse a las diferentes situaciones y condiciones endógenas que se pueden presentar en otros municipios o zonas con atractivos turísticos en este sentido.

Se ajusta a las políticas gubernamentales del país, direccionadas a la explotación turística identitaria de cada zona con su respectivo manejo y control de los recursos. Se inserta, en el Destino Cuba-Región Central e incentiva una participación comunitaria que se puede lanzar a la búsqueda, sinergia y puesta en práctica de productos turísticos sobre la base de potencialidades locales.

De igual forma, fueron emitidas algunas limitantes y sugerencias con respecto a la propuesta, las que se tomaron en cuenta para la creación del informe final. Como limitación recurrente, floreció, las limitaciones económicas y materiales actuales para la implementación de la ruta turística.

En sentido general, la valoración de la propuesta de ruta por el legado africano de Yaguajay, concluye con un juicio favorable y se reconoce su posible contribución al desarrollo local y turístico del municipio a partir de su implementación.

\section{Conclusiones}

El diseño de una ruta turística por los principales espacios donde se ha evidenciado el legado africano en Yaguajay como alternativa para contribuir al desarrollo local; se ha desarrollado siguiendo una lógica de etapas o fases. Estas fases que se desarrollan en la investigación, resultan viables en las condiciones y posibilidades actuales del municipio con respecto a su política de desarrollo turístico. La propuesta de diseño, fue valorada favorable, a partir del criterio de especialista.

La propuesta de Ruta Turística "El Legado Africano de Yaguajay", concibe un recorrido por atractivos históricos y culturales relacionados a la presencia africana en el territorio. La misma cuenta con una serie de factores que se vinculan a su principal objetivo, para que sea atrayente y sustentable en caso de implementarse. Se destacan; las ofertas de actividades y servicios complementarios, la creación de un logo para su imagen turística, así como, una propuesta de operación. 


\section{AMAZÚNAS}

\section{Bibliografía}

Arredondo, P.N. (2013). Propuesta para el diseño de rutas turísticas culturales "El caso del sur del estado de Jalisco, México". Turismo \& Sociedad, 6, 324-344

Ausina, M. (2014). Propuesta de proyecto de desarrollo turístico local para la zona rural sureste del Municipio Caibarién. (Tesis de Licenciatura en Turismo). Centro de Estudios Turísticos, Facultad de Ingeniería Industrial y Turismo. Universidad Central "Marta Abreu" De Las Villas, Santa Clara.

Bigné, J., Font, X. y Andreu, L. (2000) Marketing Estratégico en Destinos Turísticos. Madrid, España: ESIC.

Borroto, D.E. (2017). Revalorización del patrimonio industrial azucarero de Yaguajay para el desarrollo del turismo cultural. (Tesis de maestría), Universidad de Sancti Spíritus "José Martí Pérez", Yaguajay.

Boullón, R. C. (2006). Espacio turístico. México: Trillas.

Brito, J. (2011). Plan de Acciones encaminado a impulsar el desarrollo local de la ciudad de Santa Clara integrado a la actividad turística (Tesis presentada para optar por el Título de Licenciado en Turismo). Universidad Central "Marta Abreu" de Las Villas, Villa Clara, Cuba.

Cardet, E., Palao, R y González, Y. (2018). Procedimiento para el diseño de productos turísticos basados en el patrimonio de un municipio. Retos de la Dirección, 12(1), 1-16.

Castelli, L., Spallasso, V., \& Aristarain, G. (2007). Planificación y conservación del paisaje: herramientas para la protección del patrimonio natural y cultural. Fundación Naturaleza para el futuro.

Recuperado

de http://157.92.88.55/bitstream/handle/filodigital/3935/uba_ffyl_p_2016_geo_Ecolog\%C3\%ADa $\% 20 \mathrm{y} \% 20 \mathrm{Biogeograf} \% \mathrm{C} 3 \%$ ADa.pdf?

De Madariaga, C. J., \& Asencio, F. S. (2018). Patrimonio cultural inmaterial de la humanidad y turismo. International journal of scientific management and tourism, 4(2), 349-366. Recuperado de file:///C:/Users/OK/AppData/Local/Temp/Dialnet-

PatrimonioCulturalInmaterialDeLaHumanidadYTurismo-6640383.pdf

De Mahieu, G., Bozzano, J., Toselli, C., \& ten Hoeve, A. (2003). Comunidad local, patrimonio, ocio y desarrollo sustentable. Análisis sectoriales: Estudio Compartido sobre Turismo y Cultura. http://ingreso.usal.edu.ar/archivos/imae/otros/a_ocio-05.pdf

Díaz, A. H. (2017). La concepción de comunidad en el principio de Autodesarrollo Comunitario desde la sociología clásica europea. (Doctorado en Ciencias Sociológicas), Universidad Central - Marta Abreull de Las Villas, Santa Clara, Cuba.

Domínguez, D. C., García, E. G. y Barrientos-Baéz, A. (2019). La importancia del turismo cultural como medio de dignificación del turista y de la industria. Mediaciones Sociales, 18, 59-69.

Font, A.E. (2017). Actividades para la salvaguardia de las tradiciones culturales afrocubanas en el Barrio África de Yaguajay. (Tesis en opción al Título Académico de Máster en Gestión del Desarrollo Local), Universidad de Sancti Spíritus, Yaguajay.

Forneris, L. (2014). Diagnostico para el desarrollo del turismo rural comunitario en el Parque Nacional Lanín.

Grupo de Desarrollo Local (2016). Actas de las sesiones de trabajo del Grupo de Desarrollo Local del municipio de Yaguajay. Yaguajay, Sancti Spíritus. Gobierno Local (Archivo)

Guanche, J. (2010). La Ruta del Esclavo Principales actividades del Comité Cubano. In P. UNESCO (Ed.). La Habana, Cuba.

Guanche, J. y Barnet, M. (2009). Conferencia sobre La Ruta del Esclavo. La Habana. Conferencia inicial del Taller de antropología social y cultural afroamericana. Actividades con motivo del evento de la Casa de África, Oficina del Historiador de la Ciudad (Ciudad de La Habana) 
Hernández, J. (2011). Los caminos del patrimonio. Rutas turísticas e itinerarios culturales. Revista Pasos, 9(2), 225-236.

Hernández, Y. (2017). Evaluación de los productos turísticos del Parque Nacional Caguanes. Contribución al desarrollo local sostenible. (Tesis de maestría), Universidad de Sancti Spíritus "José Martí Pérez" Yaguajay.

Hernández, Y.F. (2019). Análisis comparativo del sector turístico en la Isla de Cuba y Mallorca. (Tesis de grado Turismo), Universidad de las Islas Baleares, Mallorca.

Ibarra-Michel, J. P. y Velarde, M. (2016). Rutas turísticas sustentables como alternativa de comunidades rurales. Estudios turísticos en regiones de México

Ley $\mathrm{N}^{\circ} 81$ del CITMA. Gaceta Oficial de de la República de Cuba, edición extraordinaria, 11 de julio de 1997, La Habana.

Méndez, E. O., y Szmulewicz, P. (1999). ¿Qué, cómo y a quién vender turismo? Gestión turística, (4), 2.

Nogueda, V. C. H. (2016). Preformismo, fordismo y postfordismo en el turismo; modelos para un análisis del turismo. Turismo y desarrollo local, (21)

Ochoa, P. N. A. (2013). Propuesta para el diseño de rutas turísticas culturales "El caso del sur del estado de Jalisco, México" Turismo \& Sociedad, 6, 324-344.

Partido Comunista de Cuba (2016). Actualización de los lineamientos de la política económica y social del Partido y la Revolución para el período 2016-2021. $7^{\circ}$ Congreso del Partido Comunista de Cuba. La Habana. http://media.cubadebate.cu/wp-content/uploads/2017/07/PDF-321.pdf

Pelegrín, L., Sabín, R., y Martínez, O. (2018). El ciclo de vida del producto turístico. Trinidad de Cuba como caso de estudio. Rehuso, 3(2), 1-12. Recuperado de https://revistas.utm.edu.ec/index.php/Rehuso/article/view/1370/1247

Ponce, W.P., Ramírez, J.F. y Pérez, I. (2018). Resiliencia del turismo ante fenómenos naturales. Comparación de casos de Cuba y Ecuador. COODES, 6, 225-240.

Porto, J y Merino, M. (2016). Definición de Ruta Turística. Definición. Recuperado de https://definicion.de/ruta-turistica/.

Rausell, P. (2007). Cultura. Estrategias para el desarrollo local. Madrid: Ministerio de asuntos interiores.

Rodríguez, S. M. S. (2019). Planificación integral del turismo: un enfoque para América Latina. Trillas.

Salinas, $\quad$ E., $\quad$ Salinas, $\quad$ E. $\quad$ y $\quad$ Mundet (2019) El turismo en Cuba: Desarrollo, retos y perspectivas. Rosa dos Ventos - Turismo e Hospitalidade, 11(1), 23-49, Recuperado de http://dx.doi.org/10.18226/21789061.v11i1p23.

Sánchez, S. L., Ramírez, J.F. y Pérez, I. (2020). Procedimiento para el diseño de productos agroturísticos. Cooperativismo y Desarrollo, 8(2), 166-182.

Santos, C.A.J. (2017). El turismo como factor de desarrollo. El caso de Sergipe. Brasil. (Tesis en opción al grado de doctor), Universidad de Barcelona, España.

Szmulewicz, P. y Veloso, K. (2013). Diseño de rutas turísticas en áreas rurales y naturales: Orientaciones metodológicas. En Turismo rural y áreas protegidas (pp. 99-118). Síntesis

UNESCO. (1972). Convención sobre la protección del patrimonio mundial, cultural y natural. Unesco.

UNESCO. (2019) Sitios de la Ruta del Esclavo. Recuperado de http://www.lacult.unesco.org/docc/Ruta_del_esclavo_WEB.pdf

Zulueta, M. (2015). Procedimiento para la determinación del potencial turístico en comunidades cercanas al parque nacional Caguanes del municipio Yaguajay. (Máster en Gestión Turística), Universidad Central "Marta Abreu" de Las Villas, Santa Clara. 